International Journal on Cybernetics \& Informatics (IJCI) Vol. 4, No. 2, April 2015

\title{
Control Strategy of Prosthetic Leg using SMART DEVICE
}

\author{
Y.Kalyana Chakravarthy ${ }^{1 *}$ A. Siva Kumar ${ }^{2}$, K.Susmitha ${ }^{2}$, D.Tarun ${ }^{3}$ and A.Srinath ${ }^{4}$ \\ ${ }^{1}$ K L University/Mechanical Engineering, Vaddeshwaram, Guntur District, India \\ ${ }^{2}$ K L University/Mechanical Engineering,Vaddeshwaram, Guntur District, India
}

\begin{abstract}
From past few decades prosthetics is aiding in improving the life style of the amputees. The major aspect of concern in the existing prosthetic technology is controlling the speed of the prosthetic leg. The stance phase control of prosthetic can be achieved, but it is found to fail at varying speeds. This works concentrates on the pathway to control and vary the torques of the prosthetic leg using the Bluetooth interface. The programmed Aurdino is connected to a Bluetooth of the smart device and can be operated at varying speeds thus overcoming the identified drawback. An algorithm for developed process is also generated for effective understanding and application.
\end{abstract}

\section{KEYWORDS}

Prosthetics, Control, torques, Aurdino, Bluetooth

\section{INTRODUCTION}

In every walk of life we came across many individuals who have lost their legs(limbs) owing to various cases like diseases, fatal accidents or inmilitary-marathon attacks. Any of these incidents result to loss of the limbs and the individual is left as physically challenged and their battle starts to lead the life as patients and this feeling impacts profoundly in every aspect of their lives, emotionally and also physically. A statistical analysis on person having disability in India is discussed. According to a survey report: SARVEKSHANA $36^{\text {th }}$ and $47^{\text {th }}$ rounds of National Simple Survey Organization, Department of Statistics, Government of India, the percentage of Disability in India is expressed as follows:

Table 1: Percentage of Disability in India as per $36^{\text {th }}$ and $47^{\text {th }}$ rounds of NSSO Survey [1]

\begin{tabular}{|c|c|}
\hline $\begin{array}{c}\text { Type of Disability } \\
\text { (Expressed as \% } \\
\text { over the Total } \\
\text { Disability) }\end{array}$ & Percentage \\
\hline Physical Disability & 41.32 \\
\hline Visual Impairment & 10.32 \\
\hline Hearing Impairment & 8.36 \\
\hline Speech & 5.06 \\
\hline $\begin{array}{c}\text { Locomotion } \\
\text { Disability }\end{array}$ & 23.04 \\
\hline Overlapping & 11.54 \\
\hline
\end{tabular}

DOI: $10.5121 /$ ijci.2015.4208 
International Journal on Cybernetics \& Informatics (IJCI) Vol. 4, No. 2, April 2015

To overcome such abnormalities in early years itself, a technology was implemented, and the technology is known as prosthesis. In the year 1946, the advancement over the lower limb attachment was created at university of California and these advancements were updating till now accordingly. From rock era to present day various technologies and mechanisms are used for prosthetics. The control of the prosthetic device plays a vital role.

For some extent this work helps to provide solution for victim to walk normally without any support. The proposal is to control prosthetic leg through wireless communication technology with major flexibilities updated till now.Usage of Aurdino and Bluetooth interface to control over the servo motor is adequate (in embedded developed kit). Aurdino BT is an Aurdino board with built in Bluetooth module, allowing for wireless communication. A code is dumped in the Aurdino by connecting it to the system. Thistechnology presently exists and is used for controlling various home appliances [4]. This proposal tries to apply Bluetooth interface to control the speed of the prosthetic leg.

A proposed design of the Prosthetic Leg shown in figure 1 is considered as the basic model which is to be controlled. The length of the leg are taken using the anthropometric study done [2]. The model is developed onSOLIDWORKS software and then a motion analysis is done on the same solver.

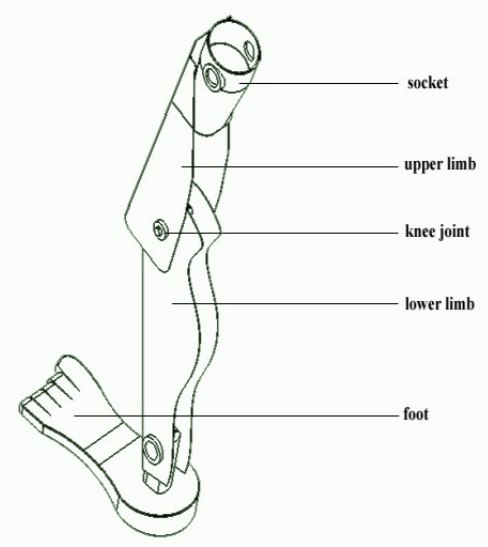

Figure 1: Model of Prosthetic Leg developed in Solid work

\section{GaIt CyCle}

The GAIT investigation is the exploration of human locomotion, utilizing the eye and the mind of spectators, augmented by instrumentation for measuring body movements, body mechanics, and the activity of the muscles [3]. Walk investigation is utilized to evaluate, arrange, and treat people with conditions influencing their capacity to walk [4].

The GAIT cycle has two essential parts, the swing stage and the stance stage [3].

Stance: stage in which the appendage is in contact with the surface.

Swing: stage in which the foot is buzzing around for appendage progression.

The phases of the gait cycle of a normal leg are shown in figure 2. Considering this walk cycle, both legs experience same stages at certain interim of time. At the point when the movement is that being said both the legs experience these stages one after other at equivalent intervals of time. 
International Journal on Cybernetics \& Informatics (IJCI) Vol. 4, No. 2, April 2015
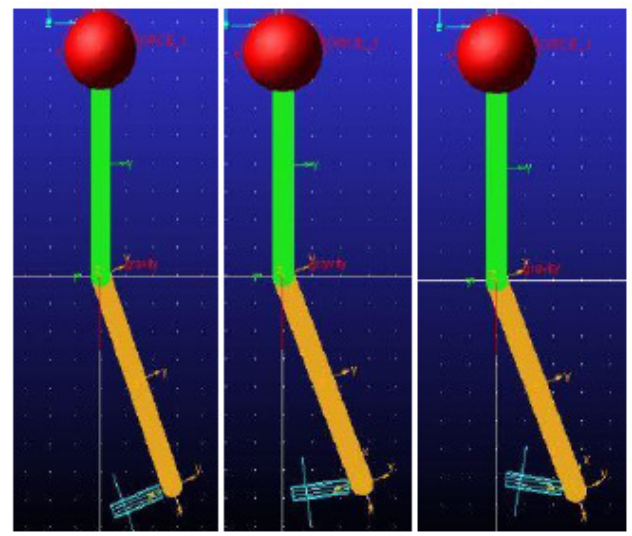

Figure 2: GAIT Cycle Phases [6]

The experimental setup for the electronics design of the prosthetic leg is shown below in the figure 3. Timings of different movements of the prosthetic leg is observed and calibrated. These movements are dumped in the microcontroller to get the exact movements on the prosthetic leg and to be same as that of a sound leg.

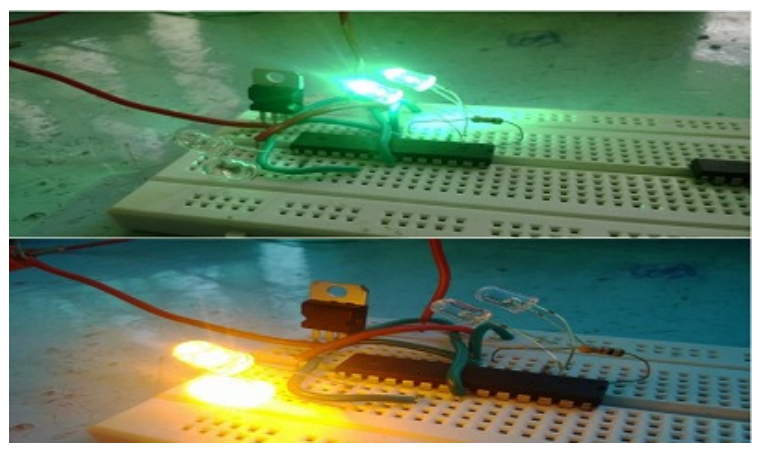

Figure 3: Experiment Setup for imitating movements of the healthy leg for Prosthetic Leg

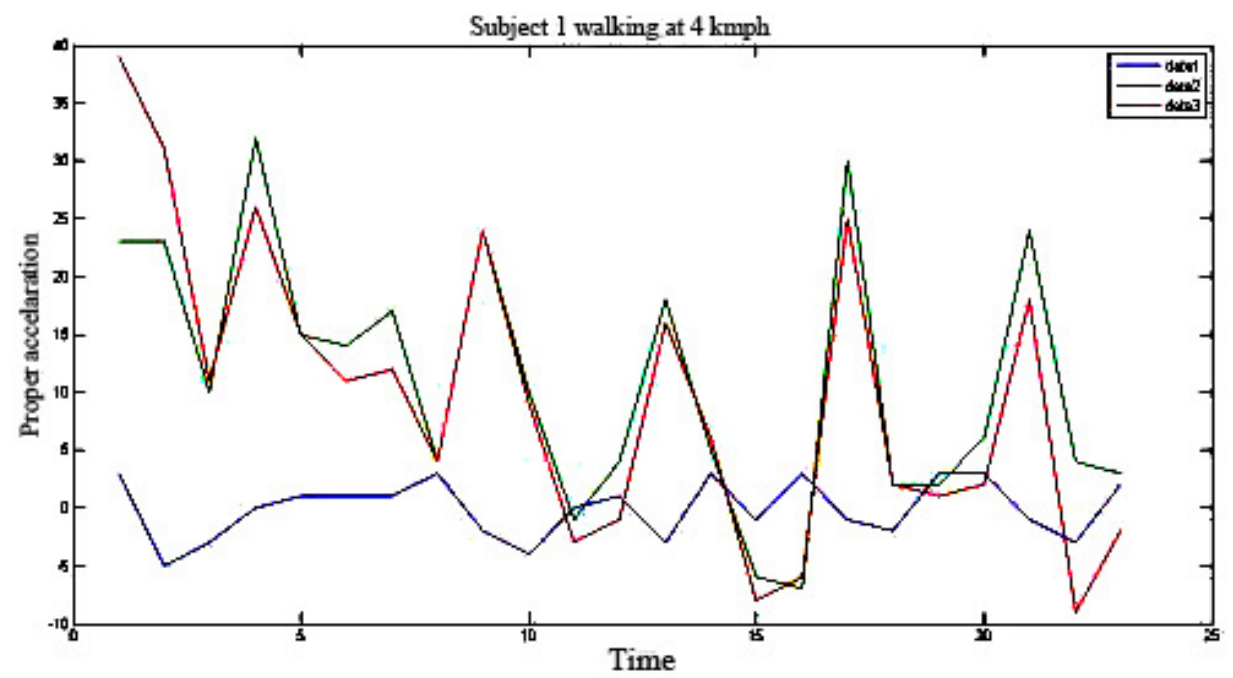

Figure 4: Accelerometer values of a typical subject walking at 4Kmph [3] 
International Journal on Cybernetics \& Informatics (IJCI) Vol. 4, No. 2, April 2015

The graph in figure 4gives the pathway to control the GAIT dynamics of the prosthetic leg which imitates the movement of the healthy leg. To achieve that process an algorithm is presented in the next session of the work.

\section{Algorithm}

The range of ankle motion calculated using a potentiometer falls between -5 to 115 degrees. The setup initialization is done according to the range identified. Bluetooth module is interfaced with Aurdino Board, establishing the connection using a smart device. Command programming is done with respect to the values obtained from the potentiometer. The program is dumped onto the Aurdino board and the whole system is powered on using a battery of maximum 12 volts capacity. The algorithm discussed above is illustrated below in figure 5 .

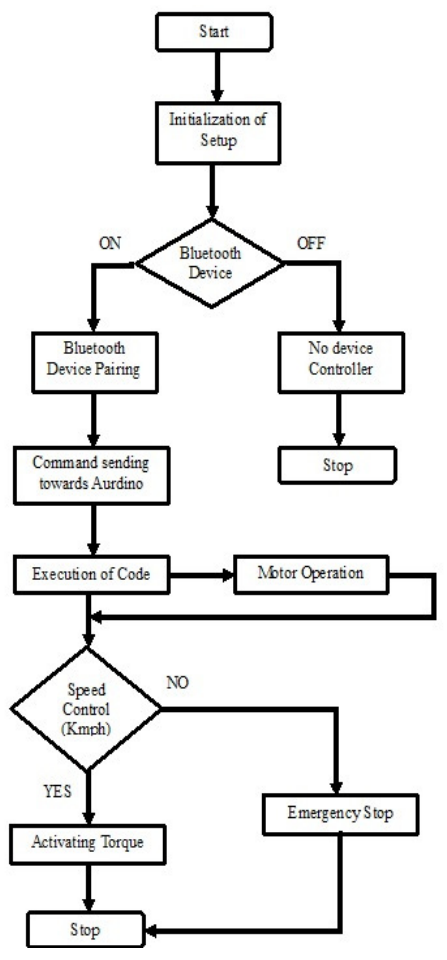

Figure 5: Algorithm Representation for Control of Torques using Bluetooth Interface

\section{Methodology}

The control's (ON, OFF) for the prosthetic leg untilnow was embedded on the prosthetic-leg itself. In the present work, the controlling will be through the interface of wireless communication device. A circuit designed using ATMEGA328 IC with a motor driver and the other required peripherals. Here Bluetooth module is used for interfacing, and communication purpose through wireless technology. Whereas IC 7805 is used as voltage dropper for the following process. Bluetooth module requires only 3.3volts so from AT-MEGA328 IC a voltage divider is implemented. And then the voltage received by the Bluetooth module will be (3.3v) but for ATMEGA328 requires only 5 volts it will be received from IC 7805. The input to this IC was in between 5 to 10 volts for the purpose of oscillations, Oscilloscope of $16 \mathrm{MHz}$ was connected for the circuit. The minimum and max requirement of an analog value is 20 and (250) respectively. 
And the coding was done accordingly. This whole circuit was inserted in the prosthetic leg during developing process.

The Bluetooth antenna in our module picks up the packets sent from the smart device. Subsequently, these packets containing the appliance status commands are pipelined through ATMEGA328 microcontroller and the designed analogue circuitry according to the definition of each output [7] as shown in the figure 6. Software was developed in the smart devices and then controls were impelled up to 10 for the purpose of user interface and simplicity then prosthetic leg can be controlled by smart device through Bluetooth interface[5]. In this an emergency stop button is provided, which has a major role during the time of any obstacles during GAIT cycle. The Bluetooth technology was so efficient and portability was adequate with the higher security.The main objective of this is to avoid sudden obstacles in the path followed by the person. Controls for various speeds are designed and implemented along with

an emergency stop system using various peripherals such as Bluetooth, Aurdino Board and handheld smart devices. The prototype of our designed prosthetic leg was shown in figure 7.

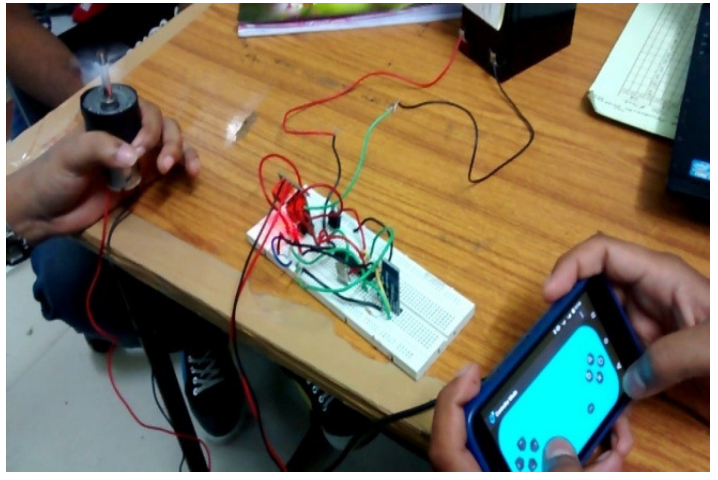

Fig-6: Experimental Setup for Controlling Actuator

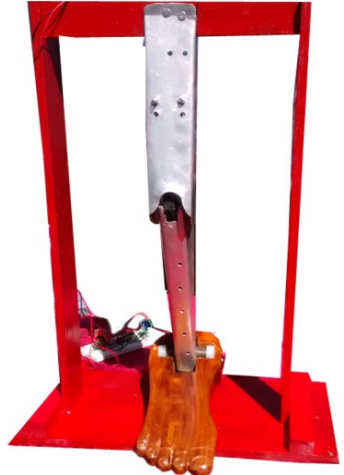

Fig-7: Designed prototype of a prosthetic leg

\section{CONCLuSiON}

The robotic Prosthetic leg developed can be attached to the above knee amputees. The torque control of the prosthetic leg at various speeds can be changed using the Smart device. But this model may fail at the rocky terrains, while climbing slopes. This limitation can be tried to be overcome, through the future work by means of replicating the motion of a sound leg of the same human onto the prosthetic leg by means of Haptics technology.

\section{REFERENCES}

[1] "Country Profile on Disability, India", Japan International Cooperation Agent, Planning and Evaluation Department, March 2002

[2] Y. Kalyan Chakravarthy, D. Tarun, A. Srinath, “ Estimation of Body Segment Weights for Prosthetic Legs suitable to Indian Amputees", International Journal of Applied Engineering Research, Vol 9 No: 20(2014) , pp:7453-7462

[3] Y. Kalyan Chakravarthy, R Harish Kumar, B Deepika, ASrinath "Haptics Based Robotic Prosthetic Leg”, International Conference on Mechatronics, Robotics and Structural Analysis (MEROSTA 2014), July 2014.

[4] http://www.optoGAIT.com/Applications/GAIT-Analysis 
International Journal on Cybernetics \& Informatics (IJCI) Vol. 4, No. 2, April 2015

[5] R.A. Ramlee et.al. "Bluetooth Remote Home Automation System Using Android Application", The International Journal of Engineering and Sciences (IJES), 2013, volume 02 issue 01, pp: 149153.

[6] Y. Kalyan Chakravarthy, J Harish, D Tarun, A Srinath, "Estimation of Joint Positions and Velocities for the Robotic Prosthetic Leg”, International Conference on Advances in Design and Manufacturing (ICAD\&M'14), December 2014.

[7] R.piyarae, M.Tazil, "Bluetooth based home automation system using cell phones", 15th International Symposium on Consumer Electronics (IEEE),2011. 